\title{
Uncertainties associated with assessing the public health risk from Legionella
}

\author{
Harriet Whiley ${ }^{1}{ }^{*}$, Alexandra Keegan ${ }^{2}$, Howard Fallowfield ${ }^{1}$ and Kirstin Ross ${ }^{1}$ \\ ' Health and the Environment, Flinders University, Adelaide, SA, Australia \\ 2 South Australian Water Corporation, Adelaide, SA, Australia
}

\section{Edited by:}

Christina M. Vandenbroucke-Grauls, VU University Medical Center, Netherlands

\section{Reviewed by:}

Tamas Szakmany, Cardiff University, UK

Li Xu, Cornell University, USA

\section{${ }^{*}$ Correspondence:}

Harriet Whiley, Health and the Environment, Flinders University, GPO Box 2100, Adelaide 5001, SA, Australia

e-mail: harriet.whiley@flinders.edu.au
Legionella is an opportunistic pathogen of public health concern. Current regulatory and management guidelines for the control of this organism are informed by risk assessments. However, there are many unanswered questions and uncertainties regarding Legionella epidemiology, strain infectivity, infectious dose, and detection methods. This review follows the EnHealth Risk Assessment Framework, to examine the current information available regarding Legionella risk and discuss the uncertainties and assumptions. This review can be used as a tool for understanding the uncertainties associated with Legionella risk assessment. It also serves to highlight the areas of Legionella research that require future focus. Improvement of these uncertainties will provide information to enhance risk management practices for Legionella, potentially improving public health protection and reducing the economic costs by streamlining current management practices.

Keywords: Legionella, L. pneumophila, risk assessment, OMRA, Legionellosis, public health

\section{INTRODUCTION}

Legionella spp. is the causative agent of Legionellosis and has been identified as a public health concern since 1976 (Fields et al., 2002; Bartram et al., 2007; Berger, 2012). Currently, government bodies rely on risk assessment models to inform the development of regulatory tools for the control of Legionellosis (Cooper et al., 2004). Current Legionella risk assessments may be compromised by uncertainties in Legionella detection methods, strain infectivity and infectious dose. This paper follows the EnHealth Risk Assessment Framework (Figure 1) developed in Australia to review current knowledge of Legionella risk and discuss the uncertainties and assumptions made. The EnHealth risk assessment framework was adopted by the Australian government to provide a national approach for assessing human health risks from environmental hazards. It provides a benchmark for risk assessments that are being undertaken for a wide variety of projects by governments and industry in Australia (Priestly et al., 2012). The uncertainties associated with each component of the risk assessment framework are collated in Figure 2 and provide a useful tool when evaluating data used for Legionella risk assessment.

\section{RISK IDENTIFICATION}

Worldwide, Legionella pneumophila is the most common causative agent of Legionellosis (Buchbinder etal., 2002). Recently, a global increase in the incidence of reported Legionellosis has been observed (Centers for Disease Control and Prevention, 2011; Beauté etal., 2013). In 2011, there were 4897 confirmed Legionellosis cases across Europe (incidence rate of 0.97 cases per 100,000; European Centre for Disease Prevention and Control, 2013). and 4,202 cases across the United States (incidence rate of 1.36 cases per 100,000; Centers for Disease Control and Prevention, 2013a). In 2013, Australia recorded 2.2 cases of Legionellosis per 100,000 (Department of Health, 2014). The true incidence of Legionellosis may be much higher as many community acquired cases go unreported (Marston et al., 1997; Todd, 2005).

Legionellosis outbreaks are primarily associated with artificial aquatic environments (Fields et al., 2002). Hence, the risk assessment for Legionella is especially important for public health officials and managers responsible for maintenance of water distribution systems and cooling towers within industrial or public buildings (Cooper et al., 2004). Risk identification is the first component of the risk assessment framework, for Legionella this is limited as the true incidence of Legionellosis is unknown and it has been estimated that the true incidence of Legionellosis could be 20 times greater than the currently reported incidence (Marston et al., 1997). Many Legionellosis community acquired cases go unreported, which places the focus of nosocomial infection and makes assumptions regarding disease epidemiology within the whole community difficult.

\section{HAZARD ASSESSMENT}

Legionellosis collectively refers to clinical syndromes as a consequence of Legionella infection (Fields et al., 2002). This includes Pontiac fever, a self-limiting febrile illness and Legionnaires diseases, a severe multisystem illness involving atypical pneumonia (Buchbinder et al., 2002; Fields et al., 2002; Bartram et al., 2007). The mortality rates of Legionellosis are highly variable and can range from 1 to $80 \%$, depending on the underlying health of a patient, promptness of diagnosis and treatment and whether the disease is nosocomial, sporadic or part of an outbreak (Bartram et al., 2007; Diederen, 2008). Currently, there is no consensus as to why exposure to L. pneumophila may result in either Pontiac fever or Legionnaires disease (Diederen, 2008; Remen et al., 2011). Remen et al. (2011) identified cases of Pontiac fever from 104 nurses working at 19 different retirement homes over a 4 month 


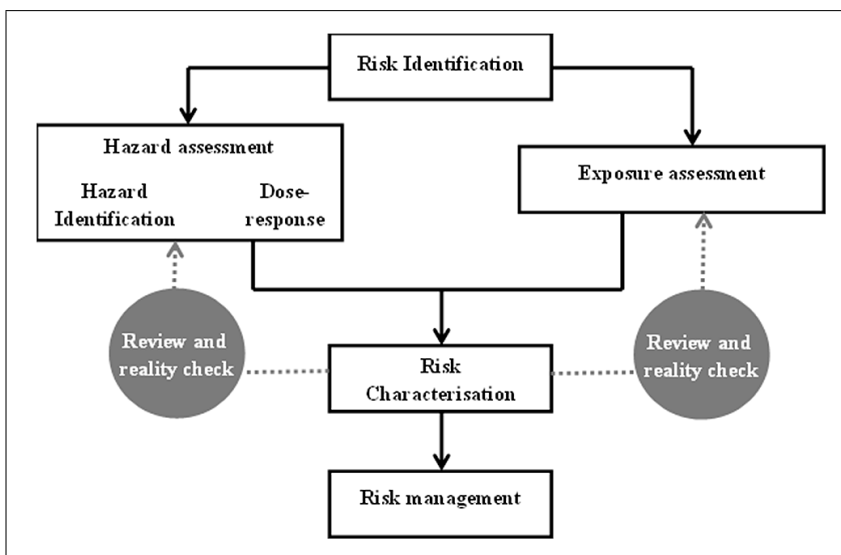

FIGURE 1 | EnHealth risk assessment framework adapted from Priestly et al. (2012).

period and found no association with concentrations of Legionella detected from the retirement village showers and cases of Pontiac fever. Occasionally simultaneous outbreaks of Pontiac fever and Legionnaires' disease from the same source have been observed (Bartram et al., 2007; Euser et al., 2010). A greater understanding of the epidemiology of these vastly different clinical outcomes would significantly improve Legionella risk assessment models. In 2007 the overall case fatality rate for reported cases of Legionellosis across Europe was 6.6\% (Joseph and Ricketts, 2010) and from 2005 to 2009 the case fatality rate was $8 \%$ across the United States (Centers for Disease Control and Prevention, 2011). The annual cost of hospitalisations due to Legionellosis in the United States is estimated to exceed US\$716 million (Giambrone, 2013).

There are limited data regarding human dose response for L. pneumophila and the concentration of Legionella required to result in an outbreak is unknown (O'Brien and Bhopal, 1993; Armstrong and Haas, 2007a). The organism is ubiquitous to many natural and artificial environments which suggest people are frequently exposed to low concentration of the organism with no consequence or asymptomatic production of Legionella antibodies (Bartram et al., 2007). This was demonstrated by Boshuizen et al. (2001) who investigated an outbreak of Legionnaires disease

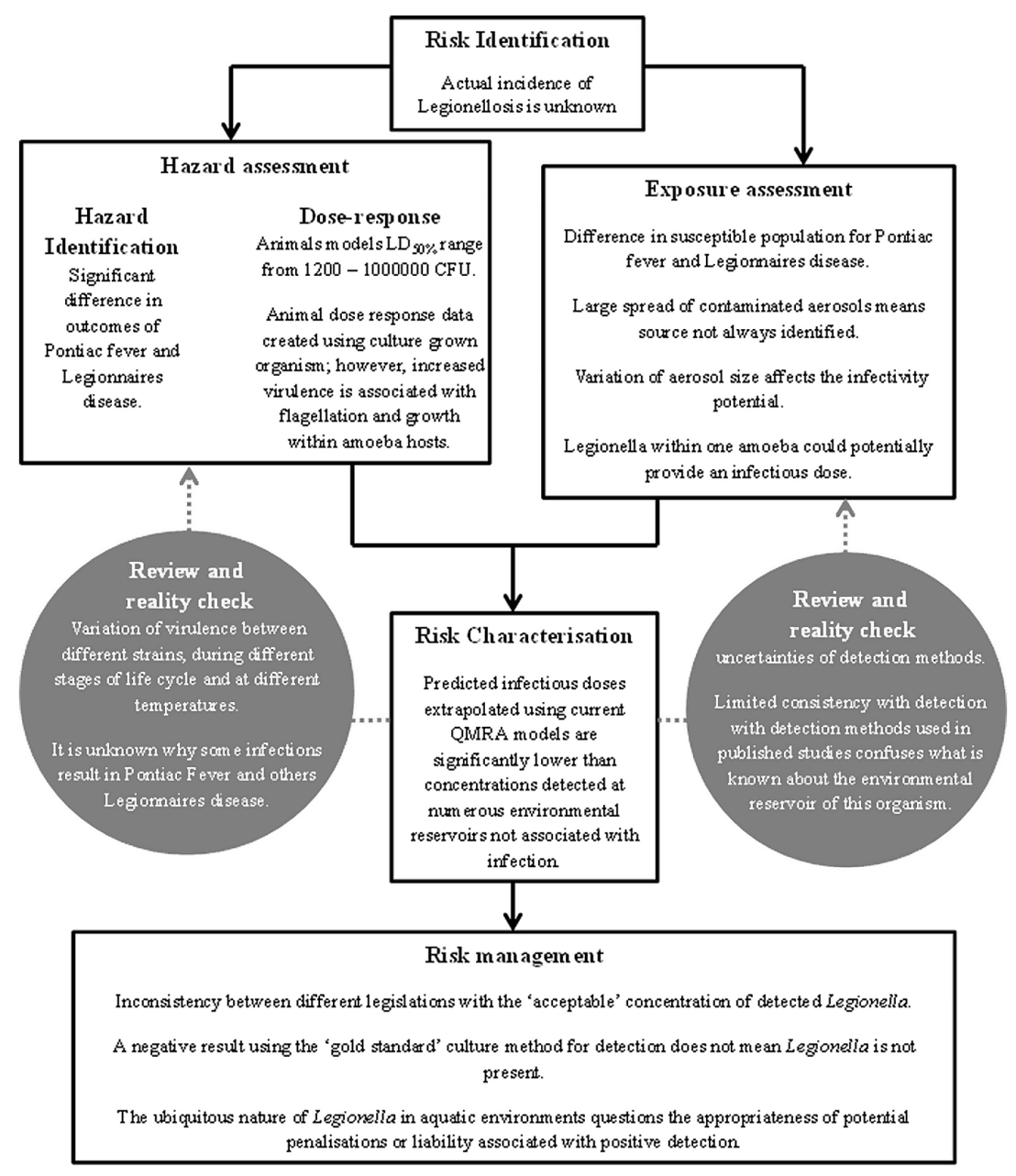

FIGURE 2 | Uncertainties of Legionella risk assessment highlighted through each step of the EnHealth risk assessment frame work. 
caused by a display whirlpool spa at a floral trade show and found that 742 exhibitors without Legionnaires disease had higher average antibody levels than the general population. The exhibitors were surveyed regarding their whereabouts during the fair and those who ventured closer to the whirlpool spa had higher antibody levels. The data from animal models for Legionella dose response have been used for quantitative microbial risk assessment (QMRA) purposes. In vitro inhalation exposure data for L. pneumophila is available for guinea pigs (Davis et al., 1982; Breiman and Horwitz, 1987), mice (Wright et al., 2003), rats (Davis et al., 1982), marmosets (Baskerville et al., 1983), and monkeys (Kishimoto et al., 1979; Baskerville et al., 1983). However, the infectious dose $\left(\mathrm{LD}_{50 \%}\right)$ across these animal models range from 1200 to $1000000 \mathrm{CFU}$ (colony forming unit; Armstrong and Haas, 2007a). Guinea pigs models have been generally accepted as the most appropriate representation of human dose response for L. pneumophila, primarily because in vitro studies show similarities for Legionella uptake, survival and replication within guinea pigs and human macrophages (Rechnitzer et al., 1992; Armstrong and Haas, 2008). Armstrong and Haas (2007b) used guinea pig ID $_{50 \%}$ (12 CFU) to a to create a QMRA model for Legionella exposure (Armstrong and Haas, 2007a), the justification for using this guinea pig model was also published (Armstrong and Haas, 2008). This study used composite data from animal dose response models, average environmental concentrations from previous studies and exposure data from three outbreaks, one associated with one whirlpool spa and two hot spring spas. From this QMRA model the predicted infectious dose from the whirlpool spa was a mean of $10 \mathrm{CFU}$ and had a 95\% range of $1.3-34$ $\mathrm{CFU}$, and the predicted infectious dose for the two hot spring spas was a mean of $47 \mathrm{CFU}$ with a $95 \%$ range of $24-84$ and for the other a mean of $2.3 \mathrm{CFU}$ with a $95 \%$ range of $1.1-4.1$ CFU. Although the models acknowledges uncertainties associated with the QMRA model, the final predicted infectious dose values calculated for the specific outbreaks are significantly lower compared to the concentrations of Legionella detected from environmental sources not associated with infection reported in numerous published studies (Buchbinder et al., 2002; Valster et al., 2011; Wang etal., 2012). The limitations of data used for the Legionella qMRA model were acknowledged by Armstrong and Haas (2007a). Improvements of this model can only be achieved through future research and greater understanding of Legionella epidemiology.

Uncertainties with Legionella dose response data also arise due to the large variation in virulence of environmental Legionella strains (Bollin et al., 1985b; Alli et al., 2003). Several studies have demonstrated that variation in growth temperature affect the virulence of L. pneumophila (Edelstein et al., 1987; Mauchline et al., 1994). However, even these studies are conflicting, Edelstein et al. (1987) reported L. pneumophila grown at $25^{\circ} \mathrm{C}$ were more virulent compared to those grown at $41^{\circ} \mathrm{C}$; whereas Mauchline et al. (1994) reported that L. pneumophila grown at $37^{\circ} \mathrm{C}$ were more virulent than those grown at $24^{\circ} \mathrm{C}$. Increased virulence of L. pneumophila is also associated with flagellation which is life cycle dependent and genetically associated to the expression of a virulent phenotype (Heuner and Steinert, 2003). Cirillo et al. (1999) also reported that L. pneumophila grown intracellular within an amoeba host has greater virulence than culture grown strains.

The disparity between Legionnaires disease and Pontiac fever further confounds L. pneumophila infectious dose data. Currently there is no consensus for an epidemiological definition of Pontiac fever (Tossa et al., 2006). Furthermore, some experts believe that Pontiac fever is caused by exposure to a mixture of live and dead microorganisms including endotoxins made by non-Legionella bacteria plus low doses of live or dead Legionella which are unable to cause pneumonia in the infected host. However, more research is required to confirm this assumption (Burnsed et al., 2007; Edelstein, 2007; Diederen, 2008). Legionnaires disease and Pontiac fever vary in regards to patients risk factors and disease outcomes (Diederen, 2008). The incubation period for Legionnaires disease is $2-10$ days (Bartram et al., 2007); whereas Pontiac fever has an incubation period of 30-90 h (Pancer and Stypukowska-Misiurewicz, 2002).

\section{EXPOSURE ASSESSMENT}

Men aged 40 years and over with underlying health issues including smoking, alcohol abuse, diabetes, heart disease, and other immunosuppression are the most susceptible population for community acquired or travel associated Legionnaires disease. Susceptible patients for nosocomial Legionnaires disease include transplant recipients, other immunosuppression, surgery, cancer, diabetes, treatment with respiratory devices, chronic heart or lung disease, smoking and alcohol abuse, which are also associated with higher mortality rates (Fields et al., 2002; Bartram et al., 2007). However, Pontiac fever preferentially affects the younger population and the median age range from several outbreaks was reported to be 29-32 years (Tossa et al., 2006). Age, gender, and smoking have not been observed to be risk factors for Pontiac fever (Friedman et al., 1987).

Legionella is present in a range of aquatic environments and human infection occurs through the inhalation of contaminated aerosol or aspiration of contaminated water (Bartram et al., 2007). Incidences of Legionellosis have been linked to contaminated shower heads (Hanrahan et al., 1987; Zmirou-Navier et al., 2007), spas (Jernigan et al., 1996; Benkel et al., 2000), baths (Sasaki et al., 2008) a hospital steam towel warmer (Higa et al., 2012), ice machines (Graman et al., 1997; Schuetz et al., 2009), mist generators (Mahoney et al., 1992), decorative water fountains (Fleming et al., 2000; O'Loughlin et al., 2007; Haupt et al., 2012), hospital water distribution systems (Tobin et al., 1981; Hanrahan et al., 1987) dental units (Reinthaler et al., 1988; Atlas et al., 1995) and cooling towers (Isozumi et al., 2005; Nguyen et al., 2006). L. pneumophila has also been detected in potable water and in 2011, 57.6\% of all potable water related disease outbreaks in the United States were due to Legionella spp. (Centers for Disease Control and Prevention, 2013b). A recent study also used quantitative polymerase chain reaction (qPCR) to detect Legionella spp and L. pneumophila ubiquitously through South Australian potable and reuse water distribution pipelines. Within the potable water distribution system Legionella spp and L. pneumophila was detected at maximum concentrations of $10^{6}$ and $10^{3}$ copies/mL respectively (Whiley et al., 2014). Human to human transmission of Legionella has not been observed (Albert-Weissenberger et al., 2007). 
There have been numerous studies which have investigated the production, size and spread on Legionella contaminated aerosols (Bollin et al., 1985a; Ishimatsu et al., 2001; Nguyen et al., 2006; Dutil et al., 2007; Zmirou-Navier et al., 2007; Chang et al., 2010). The ability of Legionella to access the human respiratory tract is governed primarily by the size of the aerosol. Aerosols $>10 \mu \mathrm{m}$ in diameter get captured within the nose and throat, between 5 and $10 \mu \mathrm{m}$ and aerosols can reach the upper and lower respiratory tract and between 2 and $5 \mu \mathrm{m}$ they can reach the lungs and conducting airways (Cox and Wathes, 1995). In Bollin et al. (1985a) demonstrated that $90 \%$ showerhead aerosol contaminated with L. pneumophila sampled above a shower door were between 1 and $5 \mu \mathrm{m}$ in diameter and 50\% of Legionella contaminated aerosols from facets were $1-8 \mu \mathrm{m}$ in diameter. These aerosols are small enough to efficiently transport the $L$. pneumophila into the lower respiratory system. The production of aerosols also provides Legionella a method to further spread contamination. This is particularly important for cooling towers. Nguyen et al. (2006) demonstrated that contaminated aerosols from a cooling tower identified as the source of an outbreak of legionnaires' disease spread up to $6 \mathrm{~km}$ from the cooling tower. Dennis and Lee (1988) demonstrated that virulent strains of L. pneumophila survived longer within aerosols compared to avirulent strains, which is important to consider when determining the potential spread of contaminated aerosols.

This difference in susceptible population for Legionnaires disease and Pontiac fever is a significant limitation for Legionella risk assessment. The potential for contaminated aerosols to spread considerable distances makes it challenging to identify the origin of the aerosol and limits knowledge regarding sources of Legionellosis (Nguyen et al., 2006). Variation in the size of aerosols also affects the infectivity, which makes it difficult to determine the infectious dose and what environmental concentrations are considered acceptable.

In order to quantify the risk of Legionellosis, enumeration of Legionella from a source is required. Many regulatory guidelines are based on the detection of Legionella. For example, in Australia each state has different cooling tower legislation regarding Legionella. In South Australia, Queensland and Australian Capital Territory detection of $\geq 1000$ Legionella CFU/mL from a cooling tower water sample requires mandatory reporting to the relevant health department (Australian Capital Territory Department of Health, 2005; Workplace Health and Safety Queensland, 2008; South Australian Department of Health and Aging, 2013). Whereas, in Victoria mandatory reporting is required if there are three consecutive detections of Legionella $\geq 10 \mathrm{CFU} / \mathrm{mL}$ (Department of Health, 2009). The problem with this legislation is the inherent difficulty regarding the detection of Legionella from environmental samples (Hussong et al., 1987; Centers for Disease Control and Prevention, 2005; Whiley and Taylor, 2014).

Currently, culture is considered the "gold standard" for $L$. pneumophila detection (Reischl et al., 2002). However, the slow growth rate of L. pneumophila makes the method tedious and can be inaccurate due to plate being overgrown from faster growing organism (Bopp et al., 1981; Hussong et al., 1987). Further inaccuracies occur with variation of sample holding time prior to culturing. McCoy et al. (2012) demonstrated that sample holding time significantly impacted Legionella recovery by culture, with enumerated Legionella changing by up to $50 \%$ within $6 \mathrm{~h}$ and up to $2 \log _{10}$ difference after $24 \mathrm{~h}$. In Australia the standard holding time for NATA (National Association of Testing Authorities) accredited laboratories is $<8 \mathrm{~h}$ (McCoy et al., 2012). Inaccuracies with culture enumeration may also occur if final confirmation of all Legionella isolates are not performed using an alternative method such as 16s RNA sequencing, polymerase chain reaction (PCR), latex agglutination test, or immunofluorescence antibody test. Borges et al. (2012) used the standard Legionella culturing method and found that 40 isolates from natural and artificial water samples grew on GVPC selective Legionella agar, had the same morphological "ground glass" appearance of Legionella, and when restreaked onto blood agar isolates did not grow. However, 16s RNA sequencing confirmed that the isolates were not Legionella and in fact were from the Chitinophagaceae family. Although not an issue in accredited laboratories which would complete final confirmation tests, it does present the possibility of false positives when culturing Legionella, a concept that should be considered when reading past studies relying on culture for detection.

A significant limitation of culture detection is that it does not account for the presence of viable but non-culturable (VBNC) organisms (Chang et al., 2009). Studies have shown that Legionella becomes VBNC during starvation, when exposed to high temperatures and monochloramine disinfection (Chang et al., 2007; Alleron et al., 2008). Allegra et al. (2011), compared Legionella detected from hospital water systems using culture and a flow cytometry assay to identify VBNC cells and found that VBNC cells varied from 4.6 to $71.7 \%$. The problem with the presence of VBNC Legionella is that using the viable culture method of detection a negative result does not necessarily mean that Legionella is not present. This has serious ramifications for public health protection using routine sampling.

Legionella detection using $\mathrm{qPCR}$ is becoming a popular alternative to culture methods as it has a quick turnaround time and high specificity. The main problem with qPCR is that it enumerates both live cells and intact killed cells (Delgado-Viscogliosi etal., 2009). This means there is a significant discrepancy between detection of Legionella using either culture or qPCR. A review of studies which detected Legionella from environmental samples with culture and qPCR simultaneously found that from a total of 28 studies, 2856/3967 (72\%) samples tested positive for Legionella spp. using qPCR and 1331/3967 (34\%) using culture (Whiley and Taylor, 2014). This discrepancy highlights the limitation of both the current detection methods and potential concerns with relying on these results for risk assessment purposes.

Another difficulty of detection from environmental sources is the ability of Legionella to opportunistically parasitise free living protozoa (Walser et al., 2014). Berk et al. (1998) demonstrated that vesicles expelled from amoeba may contain 20-200 Legionella; however, only one CFU was detected using culture. This study 
also demonstrated that over $90 \%$ of vesicles containing L. pneumophila expelled from Acanthamoeba polyphaga and A. castellanii were $2.1-6.4 \mu \mathrm{m}$ in diameter which is within the respirable size range. A single A. polyphaga was able to expel $25 \mathrm{~L}$. pneumophila filled vesicles over a $24 \mathrm{~h}$ period. Buse and Ashbolt (2012) demonstrated that under conditions representative of a drinking water system the maximum number of L. pneumophila release from $A$. polyphaga and Naegleria fowleri was respectively 1,348 and 385 CFU per trophozoite. Comparison of these concentrations to a guinea pig aerosol infection model (Berendt et al., 1980) demonstrated that as few as 1-75 infected amoebae within aerosols may contain enough pathogenic L. pneumophila to cause human infection.

The significant discrepancies between infectious dose models and detection methods has resulted in published studies giving Legionella counts which are potentially meaningless for risk assessment purposes. Armstrong and Haas (2007a) extrapolated animal modeling and data from 3 outbreaks of Legionellosis for QMRA modeling and predicted infectious doses or Legionella ranging from 1.3 to $47 \mathrm{CFU}$. The governments of South Australia, Queensland and Australian Capital Territory require mandatory reporting if Legionella is detected at a concentration $\geq 1000$ Legionella CFU/mL from a cooling tower water (Australian Capital Territory Department of Health, 2005; Workplace Health and Safety Queensland, 2008; South Australian Department of Health and Aging, 2013). Wang etal. (2012) used qPCR to detect Legionella in potable water from point of use at maximum concentrations of $2.3 \times 10^{3} \pm 9 \times 10^{2}$ copies/mL. Whiley et al. (2014) used qPCR to detect Legionella at a dead-end of a potable water distribution system at a maximum concentration of $10^{6}$ copies/mL. The inconsistencies of these values highlight the biggest flaw with current Legionella risk assessment and question the value of routine sampling. The discrepancies between Legionella concentrations measured using the different detection methods also make it difficult to compare findings from published studies. This makes it challenging to identify environmental sources of potential public health significance and to compare the effectiveness of different control measures and protocols.

\section{RISK CHARACTERIZATION}

Presently there are risk assessments models available for Legionella (Bentham, 2003; Mouchtouri et al., 2010; Torrisi et al., 2012). This include QMRA models for Legionella exposure from spas (Armstrong and Haas, 2007b), distributed water (Storey et al., 2004), and rainwater (Ahmed et al., 2010). These risk assessments characterize the nature and magnitude of risk associated with environmental sources of Legionellosis using the information currently available. However, often results of these risk assessments are not consistent or considerate of the literature regarding Legionella in the environment and its ubiquitous nature in aquatic environments. When utilizing risk assessments for the purpose of regulatory tools the realities of the limitation and assumptions made must be taken into consideration, particularly when considering potential cases of liability.

\section{RISK COMMUNICATION AND MANAGEMENT}

Currently in most developed countries there are many models of risk communication regarding Legionellosis including: training and education programs, management procedures and established documentation and communication procedures (Cooper et al., 2004; Bartram et al., 2007). Current risk management strategies for Legionella in built water systems are focused on maintaining overall system health to control biofilm formation. This can be achieved by maintaining water temperature at $<20^{\circ} \mathrm{C}$ or $>50^{\circ} \mathrm{C}$, periodical flushing of the system with hot water, or disinfection with biocides, copper-silver ionization, anodic oxidation or ultra violet light (Sidari et al., 2004; Bartram et al., 2007). The uncertainties associated with Legionella risk assessment presented in this paper also highlight areas requiring greater research in the future.

Routine testing for Legionella is required by most regulatory bodies. This is aimed at monitoring the effectiveness of treatment and management protocols, but also is a result of political expediency. Politicians and government officials often require routing testing for Legionella to demonstrate that the public health risk is being managed, despite the uncertainties of current detection methods. The main danger of this is the false sense of security gained from a negative Legionella test result, as there is little correlation between a positive Legionella test results using culture and human health risks (Kool et al., 1999). Communicating this concept to the public proves a challenging proposition, especially considering the fear association with public perception regarding Legionellosis (Irie et al., 2004; Laws et al., 2006).

In Japan, from 1997 to 2000 there was a significant decrease in sales of $24 \mathrm{~h}$ hot water baths due the public fear of Legionellosis after the 1996 detection of L. pneumophila in a public bath (Irie et al., 2004). In Australia, the largest outbreak of Legionellosis occurred in April 2000 and was caused by the Melbourne aquarium cooling towers. This outbreak resulted in two deaths and 111 identified cases of Legionellosis. The public fear in response to this outbreak was devastating to Melbourne's tourism, with significant trading losses and legal claims exceeding \$35 million (Laws et al., 2006).

One difficulty with communicating risk occurs when a situation is highly publicized and raises significant "public outrage," for example a cooling tower testing positive for Legionella. This causes the potential risk level to be perceived to be much higher than an actual calculated risk level. This is something which must be considered when completing Legionella risk assessments as the implementation of risk decisions has a much greater chance of success when supported by the public (Finucane, 2004).

\section{CONCLUSION}

Present regulatory models manage the risk of Legionella through strategies maintaining good system health, disinfection residuals and minimizing exposure routes. These regulatory guidelines are informed by Legionella risk assessment models which best use the information currently available. The uncertainties associated with each components of Legionella risk assessment have been highlighted in this paper. Minimizing these uncertainties will result in improved management protocols. The effectiveness of these management protocols is an important public health issue. Underestimating the risk of Legionella may have serious 
public health consequences; however, overestimating the risk may result in significant economic costs. The paper provides a tool for understanding the uncertainties associated with Legionella risk assessment and also provide an overview of the areas that require future research.

\section{AUTHOR CONTRIBUTIONS}

Harriet Whiley authored first draft of manuscript with academic input and expertise provided by Kirstin Ross, Howard Fallowfield, and Alexandra Keegan. All authors were involved in reviewing manuscript and have approved the final version.

\section{ACKNOWLEDGMENTS}

The authors would like to acknowledge The South Australian Water Corporation and the Goyder Institute for Water Research for their support of this work.

\section{REFERENCES}

Ahmed, W., Vieritz, A., Goonetilleke, A., and Gardner, T. (2010). Health risk from the use of roof-harvested rainwater in Southeast Queensland, Australia, as potable or nonpotable water, determined using quantitative microbial risk assessment. Appl. Environ. Microbiol. 76, 7382-7391. doi: 10.1128/aem.00944-10

Albert-Weissenberger, C., Cazalet, C., and Buchrieser, C. (2007). Legionella pneumophila-a human pathogen that co-evolved with fresh water protozoa. Cell. Mol. Life Sci. 64, 432-448. doi: 10.1007/s00018-006-6391-1

Allegra, S., Grattard, F., Girardot, F., Riffard, S., Pozzetto, B., and Berthelot, P. (2011). Longitudinal evaluation of the efficacy of heat treatment procedures against Legionella spp. in hospital water systems by using a flow cytometric assay. Appl. Environ. Microbiol. 77, 1268-1275. doi: 10.1128/AEM.02225-10

Alleron, L., Merlet, N., Lacombe, C., and Frère, J. (2008). Long term survival of Legionella pneumophila in the viable but nonculturable state after monochloramine treatment. Curr. Microbiol. 57, 497-502. doi: 10.1007/s00284-008-9275-9

Alli, O. A. T., Zink, S., Von Lackum, N. K., and Abu-Kwaik, Y. (2003). Comparative assessment of virulence traits in Legionella spp. Microbiology 149, 631-641. doi: 10.1099/mic.0.25980-0

Armstrong, T., and Haas, C. (2008). Legionnaires' disease: evaluation of a quantitative microbial risk assessment model. J. Water Health 6, 149-166. doi: 10.2166/wh.2008.026

Armstrong, T. W., and Haas, C. N. (2007a). A quantitative microbial risk assessment model for Legionnaires' disease: animal model selection and dose-response modeling. Risk Anal. 27, 1581-1596. doi: 10.1111/j.1539-6924.2007.00990.x

Armstrong, T. W., and Haas, C. N. (2007b). Quantitative microbial risk assessment model for Legionnaires' disease: assessment of human exposures for selected spa outbreaks. J. Occup. Environ. Hyg. 4, 634-646. doi: 10.1080/15459620701487539

Atlas, R. M., Williams, J. F., and Huntington, M. K. (1995). Legionella contamination of dental-unit waters. Appl. Environ. Microbiol. 61, 1208-1213.

Australian Capital Territory Department of Health. (2005). Cooling Towers and Warm Water Storage Systems Code of Practice. Canberra, ACT: Australian Capital Territory Government.

Bartram, J., Chartier, Y., Lee, J. V., Pond, K., and Surman-Lee, S. (eds). (2007). Legionella and the Prevention of Legionellosis. Geneva: World Health Organization.

Baskerville, A., Fitzgeorge, R., Broster, M., and Hambleton, P. (1983). Histopathology of experimental Legionnaires' disease in guinea pigs, rhesus monkeys and marmosets. J. Pathol. 139, 349-362. doi: 10.1002/path.1711390310

Beauté, J., Zucs, P., de Jong, B., and European Legionnaires' Disease Surveillance Network. (2013). Legionnaires' disease in Europe, 2009-2010. Euro Surveill. 18, $1-7$.

Benkel, D. H., Mcclure, E. M., Woolard, D., Rullan, J. V., Miller, G. B. Jr., Jenkins, S. R., et al. (2000). Outbreak of Legionnaires' disease associated with a display whirlpool spa. Int. J. Epidemiol. 29, 1092-1098. doi: 10.1093/ije/29.6.1092

Bentham, R. (2003). Risk assessment for Legionella in building water systems. Environ. Health 3:20.

Berendt, R. F., Young, H. W., Allen, R. G., and Knutsen, G. L. (1980). Dose-response of guinea pigs experimentally infected with aerosols of Legionella pneumophila. J. Infect. Dis. 141, 186-192. doi: 10.1093/infdis/141.2.186
Berger, S. A. (2012). Legionellosis: Global Status. ed. Global Infectious Disease and Epidemiology Network (GIDEON). Available at: http://www.gideononline.com/ ebooks/disease/legionellosis-global-status/

Berk, S. G., Ting, R. S., Turner, G. W., and Ashburn, R. J. (1998). Production of respirable vesicles containing live Legionella pneumophila cells by two Acanthamoeba spp. Appl. Environ. Microbiol. 64, 279-286.

Bollin, G. E., Plouffe, J. F., Para, M. F., and Hackman, B. (1985a). Aerosols containing Legionella pneumophila generated by shower heads and hot-water faucets. Appl. Environ. Microbiol. 50, 1128-1131.

Bollin, G. E., Plouffe, J. F., Para, M. F., and Prior, R. B. (1985b). Difference in virulence of environmental isolates of Legionella pneumophila. J. Clin. Microbiol. 21, 674-677.

Bopp, C. A., Sumner, J. W., Morris, G. K., and Wells, J. G. (1981). Isolation of Legionella spp. from environmental water samples by low-pH treatment and use of a selective medium. J. Clin. Microbiol. 13, 714-719.

Borges, A., Simões, M., Martínez-Murcia, A., and Saavedra, M. (2012). Detection of Legionella spp. in natural and man-made water systems using standard guidelines. J. Microbiol. Res. 2, 95-102. doi: 10.5923/j.microbiology.20120204.06

Boshuizen, H. C., Neppelenbroek, S. E., Van Vliet, H., Schellekens, J. F., Den Boer, J. W., Peeters, M. F., et al. (2001). Subclinical Legionella infection in workers near the source of a large outbreak of Legionnaires disease. J. Infect. Dis. 184, 515-518. doi: $10.1086 / 322049$

Breiman, R. F., and Horwitz, M. A. (1987). Guinea pigs sublethally infected with aerosolized Legionella pneumophila develop humoral and cell-mediated immune responses and are protected against lethal aerosol challenge. A model for studying host defense against lung infections caused by intracellular pathogens. J. Exp. Med. 165, 799-811. doi: 10.1084/jem.165.3.799

Buchbinder, S., Trebesius, K., and Heesemann, J. R. (2002). "Evalution of detection of Legionella," spp. in water samples by fluorescence in situ hybridization, PCR amplification and bacterial culture. Int. J. Med. Microbiol. 292, 241-245. doi: 10.1078/1438-4221-00213

Burnsed, L. J., Hicks, L. A., Smithee, L. M., Fields, B. S., Bradley, K. K., Pascoe, N., et al. (2007). A large, travel-associated outbreak of legionellosis among hotel guests: utility of the urine antigen assay in confirming Pontiac fever. Clin. Infect. Dis. 44, 222-228. doi: 10.1086/510387

Buse, H. Y., and Ashbolt, N. J. (2012). Counting Legionella cells within single Amoeba host cells. Appl. Environ. Microbiol. 78, 2070-2072. doi: 10.1128/aem.07392-11

Centers for Disease Control and Prevention. (2005). Procedures for the Recovery of Legionella from the Environment. Atlanta, GA: U.S. Department of Health and Human Services.

Centers for Disease Control and Prevention. (2011). Legionellosis - United States, 2000-2009. Morb. Mortal. Wkly. Rep. 60, 1083-1086.

Centers for Disease Control and Prevention (2013a). Summary of notifiable diseases - United States, 2011. Morb. Mortal. Wkly. Rep. 60, 1-117.

Centers for Disease Control and Prevention. (2013b). Surveillance for waterborne disease outbreaks associated with drinking water and other nonrecreational water - United States, 2009-2010. Morb. Mortal. Wkly. Rep. 62, 714-720.

Chang, B., Sugiyama, K., Taguri, T., Amemura-Maekawa, J., Kura, F., and Watanabe, H. (2009). Specific detection of viable Legionella cells by combined use of photoactivated ethidium monoazide and PCR/realtime PCR. Appl. Environ. Microbiol. 75, 147-153. doi: 10.1128/AEM. 00604-08

Chang, C. W., Chou, F. C., and Hung, P. Y. (2010). Evaluation of bioaerosol sampling techniques for Legionella pneumophila coupled with culture assay and quantitative PCR. J. Aerosol Sci. 41, 1055-1065. doi: 10.1016/j.jaerosci.2010. 09.002

Chang, C. W., Hwang, Y. H., Cheng, W. Y., and Chang, C. P. (2007). Effects of chlorination and heat disinfection on long-term starved Legionella pneumophila in warm water. J. Appl. Microbiol. 102, 1636-1644. doi: 10.1111/j.13652672.2006.03195.x

Cirillo, J. D., Cirillo, S. L., Yan, L., Bermudez, L. E., Falkow, S., and Tompkins, L. S. (1999). Intracellular growth in Acanthamoeba castellanii affects monocyte entry mechanisms and enhances virulence of Legionella pneumophila. Infect. Immun. 67, 4427-4434.

Cooper, A. J., Barnes, H. R., and Myers, E. R. (2004). Assessing risk of Legionella. ASHRAE J. 46, 22-27.

Cox, C. S., and Wathes, C. M. (1995). Bioaerosols Handbook. Boca Raton, FL: CRC Press. 
Davis, G., Winn, W. Jr., Gump, D., Craighead, J., and Beaty, H. (1982). Legionnaires' pneumonia after aerosol exposure in guinea pigs and rats. Am. Rev. Respir. Dis. 126, 1050-1057.

Delgado-Viscogliosi, P., Solignac, L., and Delattre, J. M. (2009). Viability PCR, a culture-independent method for rapid and selective quantification of viable Legionella pneumophila cells in environmental water samples. Appl. Environ. Microbiol. 75, 3502-3512. doi: 10.1128/aem.02878-2878

Dennis, P. J., and Lee, J. V. (1988). Differences in aerosol survival between pathogenic and non-pathogenic strains of Legionella pneumophila serogroup 1. J. Appl. Bacteriol. 65, 135-141. doi: 10.1111/j.1365-2672.1988.tb01501.x

Department of Health. (2009). Public Health and Wellbeing Regulations Part 7: Cooling Tower Systems and Legionella Risks in Certain Premises. Melbourne, VIC: Victorian Government.

Department of Health. (2014). Australia's National Notifiable Diseases Surveillance System (NNDSS). Canberra, ACT: Australian Government.

Diederen, B. M. W. (2008). Legionella spp. and Legionnaires' disease. J. Infect. 56, 1-12. doi: 10.1016/j.jinf.2007.09.010

Dutil, S., Veillette, M., Mériaux, A., Lazure, L., Barbeau, J., and Duchaine, C. (2007). Aerosolization of mycobacteria and legionellae during dental treatment: low exposure despite dental unit contamination. Environ. Microbiol. 9, 28362843. doi: 10.1111/j.1462-2920.2007.01395.x

Edelstein, P., Beer, K., and Deboynton, E. (1987). Influence of growth temperature on virulence of Legionella pneumophila. Infect. Immun. 55, 2701-2705.

Edelstein, P. H. (2007). Urine antigen tests positive for Pontiac fever: implications for diagnosis and pathogenesis. Clin. Infect. Dis. 44, 229-231. doi: 10.1086/510394

European Centre for Disease Prevention and Control. (2013). Legionnaires' Disease Surveillance in Europe, 2011. Stockholm: ECDC.

Euser, S. M., Pelgrim, M., and Den Boer, J. W. (2010). Legionnaires' disease and Pontiac fever after using a private outdoor whirlpool spa. Scand. J. Infect. Dis. 42, 910-916. doi: 10.3109/00365548.2010.509331

Fields, B. S., Benson, R. F., and Besser, R. E. (2002). Legionella and Legionnaires' disease: 25 years of investigation. Clin. Microbiol. Rev. 15, 506-526. doi: 10.1128/CMR.15.3.506-526.2002

Finucane, M. (2004). “The psychology of risk judgments and decisions," in Environmental Health in Australia and New Zealand, eds N. Cromar, S. Cameron, and H. Fallowfield (Melbourne, VIC: Oxford University Press).

Fleming, C., Caron, D., Gunn, J., Horine, M., Matyas, B., and Barry, M. (2000). An outbreak of Shigella sonnei associated with a recreational spray fountain. Am. J. Public Health 90, 1641-1642. doi: 10.2105/ajph.90.10.1641

Friedman, S., Spitalny, K., Barbaree, J., Faur, Y., and Mckinney, R. (1987). Pontiac fever outbreak associated with a cooling tower. Am. J. Public Health 77, 568-572. doi: 10.2105/AJPH.77.5.568

Giambrone, G. P. (2013). "National cost of hospitalization for Legionnaires' disease, 2001-2009," in Proceedings of the 2013 CSTE Annual Conference, Pasadena, CA.

Graman, P. S., Quinlan, G. A., and Rank, J. A. (1997). Nosocomial Legionellosis traced to a contaminated ice machine. Infect. Control Hosp. Epidemiol. 18, 637640. doi: 10.2307/30141491

Hanrahan, J. P., Morse, D. L., Scharf, V. B., Debbie, J. G., Schmid, G. P., Mckinney, R. M., et al. (1987). A community hospital outbreak of Legionellosis: transmission by potable hot water. Am. J. Epidemiol. 125, 639-649.

Haupt, T. E., Heffernan, R. T., Kazmierczak, J. J., Nehls-Lowe, H., Rheineck, B., Powell, C., et al. (2012). An outbreak of Legionnaires disease associated with a decorative water wall fountain in a hospital. Infect. Control Hosp. Epidemiol. 33, 185-191. doi: 10.1086/663711

Heuner, K., and Steinert, M. (2003). The flagellum of Legionella pneumophila and its link to the expression of the virulent phenotype. Int. J. Med. Microbiol. 293, 133-143. doi: 10.1078/1438-4221-00259

Higa, F., Koide, M., Haroon, A., Haranaga, S., Yamashiro, T., Tateyama, M., et al. (2012). Legionella pneumophila contamination in a steam towel warmer in a hospital setting. J. Hosp. Infect. 80, 259-261. doi: 10.1016/j.jhin.2011.12.011

Hussong, D., Colwell, R. R., O’Brien, M., Weiss, E., Pearson, A. D., Weiner, R. M., et al. (1987). Viable Legionella pneumophila not detectable by culture on agar media. Nat. Biotechnol. 5, 947-950. doi: 10.1038/nbt0987-947

Irie, M., Miyamoto, H., Ikeda, M., and Yoshida, S. I. (2004). A 3-year follow-up study of anti-Legionella antibodies in users of Japanese 24-hour hot water baths. J. Occup. Health 46, 68-77. doi: 10.1539/joh.46.68

Ishimatsu, S., Miyamoto, H., Hori, H., Tanaka, I., and Yoshida, S. I. (2001). Sampling and detection of Legionella pneumophila aerosols generated from an industrial cooling tower. Ann. Occup. Hyg. 45, 421-427. doi: 10.1093/annhyg/45.6.421
Isozumi, R., Ito, Y., Ito, I., Osawa, M., Hirai, T., Takakura, S., et al. (2005). An outbreak of Legionella pneumonia originating from a cooling tower. Scand. J. Infect. Dis. 37, 709-711. doi: 10.1080/00365540510012143

Jernigan, D. B., Hofmann, J., Cetron, M. S., Nuorti, J. P., Fields, B. S., Benson, R. F., et al. (1996). Outbreak of Legionnaires' disease among cruise ship passengers exposed to a contaminated whirlpool spa. Lancet 347, 494-499. doi: 10.1016/s0140-6736(96)91137-x

Joseph, C., and Ricketts, K. (2010). Legionnaires disease in Europe 2007-2008. Euro Surveill. 15, 19493. doi: 10.1097/QCO.0b013e328336835b

Kishimoto, R., Kastello, M., White, J., Shirey, F., Mcgann, V., Larson, E., et al. (1979). In vitro interaction between normal cynolmolgus monkey alveolar macrophages and Legionnaires disease bacteria. Infect. Immu. 25, 761-763.

Kool, J., Bergmire-Sweat, D., Butler, J., Brown, E., Peabody, D., Massi, D. S., et al. (1999). Hospital characteristics associated with colonization of water systems by Legionella and risk of nosocomial Legionnaires' Disease: a cohort study of 15 hospitals. Infect. Control Hosp. Epidemiol. 20, 798-805. doi: 10.1086/501587

Laws, E., Prideaux, B., and Chon, K. (2006). Crisis Management in Tourism. Wallingford: CABI.

Mahoney, F. J., Hoge, C. W., Farley, T. A., Barbaree, J. M., Breiman, R. F., Benson, R. F., et al. (1992). Communitywide outbreak of Legionnaires' disease associated with a grocery store mist machine. J. Infect. Dis. 165, 736-739. doi: 10.1093/infdis/165.4.xxxx

Marston, B. J., Plouffe, J. F., File T. M. Jr., Hackman, B. A., Salstrom, S. J., Lipman, H. B., et al. (1997). Incidence of community-acquired pneumonia requiring hospitalization: results of a population-based active surveillance study in Ohio. Arch. Intern. Med. 157, 1709-1718. doi: 10.1001/archinte.1997.00440360129015

Mauchline, W. S., James, B. W., Fitzgeorge, R. B., Dennis, P. J., and Keevil, C. W. (1994). Growth temperature reversibly modulates the virulence of Legionella pneumophila. Infect. Immun. 62, 2995-2997.

McCoy, W. F., Downes, E. L., Leonidas, L. F., Cain, M. F., Sherman, D. L., Chen, K., et al. (2012). Inaccuracy in Legionella tests of building water systems due to sample holding time. Water Res. 46, 3497-3506. doi: 10.1016/j.watres.2012. 03.062

Mouchtouri, V. A., Goutziana, G., Kremastinou, J., and Hadjichristodoulou, C. (2010). Legionella species colonization in cooling towers: risk factors and assessment of control measures. Am. J. Infect. Control 38, 50-55. doi: 10.1016/j.ajic.2009.04.285

Nguyen, T. M. N., Ilef, D., Jarraud, S., Rouil, L., Campese, C., Che, D., et al. (2006). A community-wide outbreak of Legionnaires disease linked to industrial cooling towers - how far can contaminated aerosols spread? J. Infect. Dis. 193, 102-111. doi: $10.1086 / 498575$

O'Brien, S., and Bhopal, R. (1993). Legionnaires' disease: the infective dose paradox. Lancet 342, 5-6. doi: 10.1016/0140-6736(93)91877-O

O'Loughlin, R., Kightlinger, L., Werpy, M., Brown, E., Stevens, V., Hepper, C., et al. (2007). Restaurant outbreak of Legionnaires' disease associated with a decorative fountain: an environmental and case-control study. BMC Infect. Dis. 7:93. doi: 10.1186/1471-2334-7-93

Pancer, K., and Stypukowska-Misiurewicz, H. (2002). Pontiac fever - nonpneumonic legionellosis. Przegl. Epidemiol. 57, 607-612.

Priestly, B., Ong, J., Langley, A., Dempsey, J., Davies, L., Fitzgerald, J., et al. (2012). "Environmental health risk assessment," in Guidelines for Assessing Human Health Risks from Environmental Hazards, ed. Enhealth (Canberra, ACT: Australian Government).

Rechnitzer, C., Williams, A., Wright, B., Dowsett, A. B., Milman, N., and Fitzgeorge, R. B. (1992). Demonstration of the intracellular production of tissue-destructive protease by Legionella pneumophila multiplying within guinea-pig and human alveolar macrophages. J. Gen. Microbiol. 138, 1671-1677. doi: 10.1099/00221287138-8-1671

Reinthaler, F., Mascher, F., and Stunzner, D. (1988). Serological examinations for antibodies against Legionella species in dental personnel. J. Dent. Res. 67, 942-943. doi: 10.1177/00220345880670061001

Reischl, U., Linde, H. J., Lehn, N., Landt, O., Barratt, K., and Wellinghausen, N. (2002). Direct detection and differentiation of Legionella spp. and Legionella pneumophila in clinical specimens by dual-color real-time PCR and melting curve analysis. J. Clin. Microbiol. 40, 3814-3817. doi: 10.1128/JCM.40.10.38143817.2002

Remen, T., Mathieu, L., Hautemaniere, A., Deloge-Abarkan, M., Hartemann, P., and Zmirou-Navier, D. (2011). Pontiac fever among retirement home 
nurses associated with airborne Legionella. J. Hosp. Infect. 78, 269-273. doi: 10.1016/j.jhin.2011.03.022

Sasaki, T., Matsumoto, N., Nakao, H., Katoh, T., Fukuda, Y., Nakazato, M., et al. (2008). An outbreak of Legionnaires' disease associated with a circulating bathwater system at a public bathhouse: a clinical analysis. J. Infect. Chemother. 14, 123-129. doi: 10.1007/s10156-008-0592-5

Schuetz, A. N., Hughes, R. L. M., Howard, R. M., Williams, T. C., Nolte, F. S., Jackson, D., et al. (2009). Pseudo outbreak of Legionella pneumophila serogroup 8 infection associated with a contaminated ice machine in a bronchoscopy suite. Infect. Control Hosp. Epidemiol. 30, 461-466. doi: 10.1086/596613

Sidari, F. P. III, Stout, J. E., Van Briesen, J. M., Bowman, A. M., Grubb, D., Neuner, A., et al. (2004). Keeping Legionella out of water systems. Am. Water Works Assoc. 96, 111-119.

South Australian Department of Health and Aging. (2013). Guidelines for the Control of Legionella in Manufactured Water Systems in South Australian. Canberra, ACT Australian Government.

Storey, M., Ashbolt, N., and Stenström, T. (2004). Biofilms, thermophilic amoebae and Legionella pneumophila- A quantitative risk assessment for distributed water. Water Sci. Technol. 50, 77-82.

Tobin, J. O., Swann, R. A., and Bartlett, C. L. (1981). Isolation of Legionella pneumophila from water systems: methods and preliminary results. $\mathrm{Br}$. Med. J. (Clin. Res. Ed.) 282, 515-517. doi: 10.1136/bmj.282.6263.515

Todd, B. (2005). Legionella pneumonia: many cases of Legionnaire disease go unreported or unrecognized. Am. J. Nur. 105, 35-38. doi: 10.1097/00000446200511000-00023

Torrisi, S., Cavedoni, E., Pastoris, O., Brema, C., Verri, M., Bongiorno, A. I., et al. (2012). Legionella pneumophila: risk assessment and strategy for the prevention and control of nosocomial infections. Microbiol. Med. 27, 96-100. doi: 10.4081/mm.2012.2315

Tossa, P., Deloge-Abarkan, M., Zmirou-Navier, D., Hartemann, P., and Mathieu, L. (2006). Pontiac fever: an operational definition for epidemiological studies. BMC Public Health 6:112. doi: 10.1186/1471-2458-6-112

Valster, R. M., Wullings, B. A., Van Den Berg, R., and Van Der Kooij, D. (2011). Relationships between free-living Protozoa, cultivable Legionella spp., and water quality characteristics in three drinking water supplies in the Caribbean. Appl. Environ. Microbiol. 77, 7321-7328. doi: 10.1128/aem.05575-11

Walser, S. M., Gerstner, D. G., Brenner, B., Höller, C., Liebl, B., and Herr, C. E. W. (2014). Assessing the environmental health relevance of cooling towers - A systematic review of Legionellosis outbreaks. Int. J. Hyg. Environ. Health 217, 145-154. doi: 10.1016/j.ijheh.2013.08.002
Wang, H., Edwards, M. A., Falkinham, J. O., and Pruden, A. (2012). Molecular survey of occurrence of Legionella spp., Mycobacterium spp., Pseudomonas aeruginosa and Amoeba hosts in two chloraminated drinking water distribution systems. Appl. Environ. Microbiol. 78, 6285-6294. doi: 10.1128/aem.01492-12

Whiley, H., Keegan, A., Fallowfield, H., and Bentham, R. (2014). Detection of Legionella, L. pneumophila and Mycobacterium avium complex (MAC) along potable water distribution pipelines. Int. J. Environ. Res. Public Health 11, 7393-7495. doi: 10.3390/ijerph110707393

Whiley, H., and Taylor, M. (2014). Legionella detection by culture and qPCR: comparing apples and oranges. Crit. Rev. Microbiol. doi: 10.3109/1040841X.2014.885930 [Epub ahead of print].

Workplace Health and Safety Queensland. (2008). Guide to Legionella Control in Cooling Water Systems, Including Cooling Towers, ed. Department of Justice and Attorney General (Brisbane, QLD: Queensland Government.

Wright, E. K. Jr, Goodart, S. A., Growney, J. D., Hadinoto, V., Endrizzi, M. G., Long, E. M., et al. (2003). Naip5 affects host susceptibility to the intracellular pathogen Legionella pneumophila. Curr. Biol. 13, 27-36. doi: 10.1016/S09609822(02)01359-3

Zmirou-Navier, D., Remen, T., Bauer, M., Deloge-Abarkan, M., Tossa, P., and Mathieu, L. (2007). Legionella in shower aerosols and Pontiac fever among health workers and residents in nursing homes. Epidemiology 18:S50.

Conflict of Interest Statement: The authors declare that the research was conducted in the absence of any commercial or financial relationships that could be construed as a potential conflict of interest.

Received: 05 August 2014; accepted: 05 September 2014; published online: 24 September 2014.

Citation: Whiley H, Keegan A, Fallowfield Hand Ross K (2014) Uncertainties associated with assessing the public health risk from Legionella. Front. Microbiol. 5:501. doi: 10.3389/fmicb.2014.00501

This article was submitted to Infectious Diseases, a section of the journal Frontiers in Microbiology.

Copyright (c) 2014 Whiley, Keegan, Fallowfield and Ross. This is an open-access article distributed under the terms of the Creative Commons Attribution License (CC BY). The use, distribution or reproduction in other forums is permitted, provided the original author(s) or licensor are credited and that the original publication in this journal is cited, in accordance with accepted academic practice. No use, distribution or reproduction is permitted which does not comply with these terms. 